Review

\title{
First Nations People: Addressing the Relationships between Under-Enrollment in Medical Education, STEM Education, and Health in the United States
}

\author{
Dharam Persaud-Sharma * and Joseph Burns \\ Herbert Wertheim College of Medicine, Florida International University, Miami, FL 33199, USA; \\ jburn052@fiu.edu \\ * Correspondence: dpers001@fiu.edu
}

Received: 24 October 2017; Accepted: 19 January 2018; Published: 5 February 2018

\begin{abstract}
In the United States of America, an analysis of enrollment statistics to institutions of higher education, those pursuing Science, Technology, Engineering, and Mathematics (STEM) fields, as well as those pursuing medical education show a paralleled ethnic stratification. Based upon such stratification, Native Americans consistently rank amongst the lowest demographic groups to enroll in and pursue higher education, STEM or medical education. A perturbed history of the First Nations people in the establishment of the United States of America laid the foundation for a multitude of factors contributing to current trends in health, living, and academic pursuits amongst First Nation's people. This paper aims to explore the factors underlying the lack of Native American enrollment in higher education, careers in STEM and medicine. An investigation was conducted following a broad literature review relevant to the topic, and articles were critically appraised using the Search, Appraisal, Synthesis of Analysis (SALSA) framework as well as the Standards for Reporting Qualitative Research (SRQR). Findings from such studies indicate that the Native American communities face a unique set of social circumstances rooted in a historical context, with several unmet basic needs of living required for integration, access, and pursuit of higher education.
\end{abstract}

Keywords: First Nation; Native American; medicine; education; STEM; Aboriginal; Indigenous; tribe

\section{Introduction}

In the United States, Native American (NA) students continue to lag behind non-Native American students in high school completion, post-secondary education enrollment/completion and enrollment in professional programs like medical school. Furthermore, the First Nation population continues to suffer from health disparities driven by social determinants. There is an innumerable list of historical factors that contribute to these issues, yet there is a paucity of information available with programs and methods to ameliorate these factors to improve enrollment, retention, training, and population health. This cycle perpetuates the dearth of skilled Native American personnel trained in Science, Technology, Engineering, Mathematics (STEM) fields, including medicine, from serving First Nations' people. After centuries of American colonial oppression, these populations have developed unique cultural identities. Income from gaming has transformed life for tribal members. However, this new economic prosperity does not protect against issues concerning health and education that plague Native American populations across the country.

Historically, the relationship between Native American communities and Europeans invading the North American continent laid the foundation for the surrendering of trust between the two groups. Originally, Indigenous Americans were part of a secular community. The richness of the culture was the education of their people and these lessons were passed on to each successive generation with the basis of survival emphasized through playing games, folklore, hunting and gathering. However, 
when European settlers came to what is now the North American continent in 1492, they not only seized the land but also the indigenous people and their culture [1]. Europeans forced indigenous children to be removed from their tribes, sent to boarding school to learn English, practice Christianity, and become "civilized" to the European standards. This resulted in the abandonment of cultural identity and richness that was cultivated for thousands of years. They were forced to abandon their hands-on learning style and to assimilate to Western stylized classroom learning that emphasizes rote memorization. Eventually, after nearly 300 years of an antagonistic relationship, the U.S. government allowed the establishment of the Bureau of Indian Affairs permitting tribes to preserve their cultural identity and be autonomous in their own future.

Historically, Native Americans have made numerous contributions to science, engineering and medicine. Among these are sophisticated understandings of astronomy, botany, and the medicinal uses of plants and animals, many of which contributed to western pharmacology. Based on generations of scientific inquiry, these cultures developed an intimate understanding of their natural surroundings and the diversity in which they may be utilized [2]. One such example of this is the use of the saw palmetto plant (Serenoa repens) for centuries by the Seminole and Miccosukee tribes of Florida, which served as a dietary staple of the First Nations' people. Now, Serenoa repens extracts have been refined as a core medicinal component for the treatment of benign prostatic hyperplasia [3]. Another exemplary contribution to the modern field of medicine by Native American culture is the identification and refining of salicylic acid as a key ingredient in aspirin for pain relief. Salicylic acid has been found in willow tree bark, and was commonly utilized by the First Nations' people to reduce fever and pain [4].

Yet, despite these contributory examples, Native American students continue to report challenges in achieving post-secondary education in STEM disciplines. In the field of chemical engineering, $40 \%$ of female and minority engineers report being discouraged from pursuing their career at some point in their lives [5]. In a comprehensive study of STEM education pathways in South Dakota, two key issues found to underlie the disparity of NA students in these fields include lack of academic preparation and of resources [6]. Further, they identify the lack of job opportunities in their communities, historical tensions, racism, misunderstandings and cultural differences that obstruct the pathway to higher education [6]. Beyond acceptance and matriculation to college, further challenges exist in the retention of NA students, furthering the need for support, both financially and educationally to assist in the transition for these students [6].

After more than 500 centuries of being indoctrinated and removed from their self-identity, the struggle for Native American people and communities to successfully integrate in a society rooted in mistrust has had consequential sequelae. The statistics in terms of education, life-expectancy, housing, income, health care, health-care access, and the basic needs of living including food and shelter are all substantially lower than those of non-indigenous people. It is critical to explore these disparities and to evaluate the underlying contributory factors in order to better serve these communities and provide equitable education and healthcare for the common welfare of all Americans.

\section{Methods}

Utilizing combinations of the key search terms "Native American" (NA), "American Indian" (AI), "health", "education", "disparities", "Native American and STEM", "STEM" and "inequality" across multiple databases including PubMed and Google Scholar, the authors conducted a broad literature review to support this manuscript. Further, critical articles recommended by existing networks and the references of these papers were further utilized in our identification of relevant studies. Using the aforementioned search criteria, hundreds of articles returned. Articles of interest received further investigation including determination of the Open Access availability and availability through institutional libraries. Included articles must have been published within the last decade and support the identified research question. The authors read these targeted pieces in their entirety. In the review, 40 such articles are included. The Indian Health Service target areas of emphasis served as a model for structuring the discussion of Native American health and education disparities. The authors found 
additional articles regarding historical trauma and the social determinants of health in a similar manner, albeit using narrower search criteria. The authors evaluated sources that were not critically appraised for internal and external validity based upon the authority of the authors and relevance, purpose, bias, accuracy and transparency of the publishing body prior to inclusion in the manuscript. The authors drew upon their combined post-secondary education (18 years) and community service experience (25 years) and in one case, Native American heritage, to examine the literature from peer-reviewed and non-peer reviewed publications. With the aim to review literature exploring the factors limiting people of Native American origin enrollment in both STEM and Medicine professions, the reviews were subsequently critically appraised using the Search, Appraisal, Synthesis and Analysis (SALSA) framework, as well as the Standards for Reporting Qualitative Research (SRQR). From each review, the authors identified information pertaining to the question of interest and amalgamated this data into a single document to provide a scoping review contained herein as it relates to the research question.

\section{Disparities in Native American Populations}

\subsection{Understanding Native American Demographics}

\subsubsection{Demographic Data}

National data describing demographic and health data on Native American populations is available through multiple agencies. These include the National Census and the American Community Survey (ACS) amongst others, which are administered by the U.S. Census Bureau. ACS data are generated yearly, and minority populations like Native Americans are intentionally over-sampled. All Native American tribes and Alaskan Natives are often grouped together and categorized as NA without further identification. Additionally, these reports may include individuals in either of these categories for those who indicate solely Native American of Pacific Islander (NHOPI) or NA, including those who identify as more than one race. Generally speaking, small sample sizes and a combination of NA with multiple ethnicities limit the statistical strength of these databases [7].

\subsubsection{Tribal Organization and Population Distribution}

The United States recognizes 566 Native American tribes. Per the 2010 Census, the largest in the United States include the Navajo, Cherokee, Mexican American Indian, Choctaw, Chippewa, Blackfeet, Sioux, and Creek, Apache, and Iroquois tribes. Among Alaska Natives, the largest are the Inupiat, Yup'ik, Tlingit-Haida, Aleut, Alaskan Athabascan and Tsimshian [7].

A majority of the NA population resides in eleven states-Oklahoma, California, Arizona, New York, Texas, New Mexico, North Carolina, Washington, Florida, Michigan, and Alaska [7]. Only 22\% live in areas designated as reservation territories [7]. Among Native Americans older than age $65,45 \%$ live in the Western United States, with another 33.5\% living in the South. More than $80 \%$ of this demographic resides in urban areas [7].

\subsubsection{Socioeconomic Status}

Many Native Americans are faced with a multitude of socioeconomic disparities. About 50\% of NA householders own their own homes, relative to about $64 \%$ of the overall U.S. population [7]. Nationally, only 17\% of NA aged 25 and older has a bachelor's degree, compared to 33\% of white Americans [7,8]. In this context, 'white Americans' refer to those who self-report as such per the national U.S. Census Bureau with ancestry from Europe, the Middle East or North Africa.

In 2012 , the median household income was $\$ 37,353$ for $\mathrm{NA}$, compared to $\$ 56,565$ for whites. In addition, about $26 \%$ of NA live below the poverty line, relative to $11 \%$ of whites [8]. It is estimated that $37.1 \%$ of NA individuals over age 65 were living alone in 2010 , compared to $43.0 \%$ of white elders. Urban-dwelling NA elders are more likely to live alone than those living on an Indian reservation, but less likely to experience poverty [8]. 


\subsubsection{Life Expectancy}

Although the sheer number of elderly Native Americans is increasing, the life expectancy of NA individuals continues to average three to four years below the mean for the entire populace of the United States [9]. Though those over 65 make up 14.4\% of the Caucasian population, this same demographic represents only $7.1 \%$ of Native Americans [8].

\subsection{Native American Health Disparities}

Westernization of the lifestyle of the tribes of the United States has had tremendous effects on health outcomes, as the incidence of diabetes, obesity, hypertension and substance abuse has skyrocketed in reservations across the United States [10]. The Indian Health Service identifies seven key areas of improvement in the area of community health - environmental health, behavioral health, health communication, injury prevention, health promotion, school health, and sustainability [11].

The IHS identifies "substance abuse disorders, mental health disorders, suicide, violence and behavior-related chronic diseases" as conditions that have a substantial negative impact on Native American health outcomes [12]. Healthy People 2010 identified substance abuse reduction as a key objective. The target goal was to reduce drug-induced deaths to below one per 100,000. Data from the 2011 survey estimates this rate in Native American populations as 15 such deaths per 100,000; which is higher than the national average of 9.9 [9]. More recent data shows a continued increase in the rate of drug-related deaths since the initial tracking of this statistic in 1979 at a rate of 454\% [9]. Similarly, suicide was identified as a Health People 2010 key area of improvement with a target goal of five deaths per 100,000. The 2011 surveyed data also reflects a Native American suicide rate of 17.9 per 100,000, again significantly higher than the national average of 10.8 [13]. To address these disparities, the IHS has created several programs including the Alcohol and Substance Abuse Program, Domestic Violence Prevention Initiative and Suicide Prevention Program [12]. Dozens of culturally sensitive programs have been implemented on reservations throughout the country with great success. Among these are the Clothesline Project to address domestic violence in the Chickasaw Nation, Green Dot Anti-Violence Training among the Cherokee and Stickball with the Choctaw [14].

The second focus area identified by the IHS is environmental health. The Environmental Health Services Program works in the following priority areas: "children's environment, safe drinking water, food safety, vector-borne and communicable diseases, and healthy homes" [15]. Data from 2013 reflects a $\$ 1.717$ million deficiency in the ability to provide sanitation facilities for IHS catchment areas. This numerical value represents the cost to provide services, upgrade existing facilities and cover operational costs [6]. Further, the recent protests against building the Dakota Access Oil Pipeline across NA dominant land has redirected the spotlight of concern for the sustenance of NA health, environmental stewardship, and natural resources.

Deficits in healthcare communication for Native American populations largely are due to insufficient cultural and linguistic competency of providers. This is further complicated by the lack of health literacy of the population as a whole [16]. Per the 2000 Census, $70.9 \%$ of the Native American population over the age of 25 were high school graduates compared to $80.4 \%$ nationally. For bachelor's degree attainment or higher, these percentages are 11.5 and 24.4, respectively. Further, unemployment is significantly higher in the Native American population, with $13.1 \%$ of males and $11.7 \%$ of females unemployed in 2000 compared to national averages of $5.7 \%$ and $5.8 \%$ [6].

The Health Promotion and Disease Prevention Initiative aims to provide public health programming focused on five primary areas-diabetes, nutrition, obesity, physical activity and exercise and tobacco cessation [17]. From 2002 to 2004, the age-adjusted mortality rate in which diabetes was the underlying cause was 74.2 per 100,000 in Native American populations. This is three times higher than the average for the white population in the same timeframe. However, recent data reflects that this rate is trending down. Between 2007 and 2009 the rate was 61.0, still nearly 40 percent higher than the national average [13]. The national rate of lung cancer mortality is trending downward. However, in the Native American population, this rate is increasing, though below the national average [6]. 
This is a troublesome trend that the IHS is actively seeking to address through anti-tobacco webinars, providing resources for providers and the IHS Tobacco Free campaign [18].

Another area of emphasis for the IHS is injury prevention. Injuries are the third leading cause of death for Native Americans between ages one and forty-four. The IHS has introduced multiple initiatives that have reduced the rate of mortality due to unintentional injury by 58 percent between 1973 and 2003 [19]. However, Healthy People 2010 established a target of 17.5 deaths per 100,000 due to unintentional injuries including motor vehicle crashes, falls, fires and burns, drowning, poisonings, aspirations and overdose. The 2011 Native American rate was 94.8, more than twice the national average [13]. Current training programs include the Tribal Injury Prevention Cooperative Agreement Program, Ride Safe, Sleep Safe and Training Programs and Fellowships [19].

School health is an issue area that encompasses several initiatives, including health education, healthy eating, physical activity, oral health, injury prevention, mental wellness and environmental health. By educating Native American youth on these areas of emphasis, they may be prevented in future generations. In this manner, sustainable health programming may improve the IHS surveyed health outcomes [20].

The final area of emphasis in community health identified by the IHS is sustainability. Programming development includes energy management, water conservation, sustainable buildings, sustainable acquisitions, pollution prevention, electronics stewardship and sustainable communities [21]. This division is a reflection of the importance of environmentalism in Native American culture.

\subsection{STEM, Post-Secondary, and Medical Education}

Native Americans make up about $1.2 \%$ of the entire population in the United States; however, the entire NA population only constitutes $0.4 \%$ of all bachelor degrees in engineering [22]. This under-enrollment on a global education scale of NA populations completing/enrolling in postsecondary education in the USA is astonishing. While many of the literature available discuss the limiting factors which prevent NA enrolling/completing such educational goals, many of these opinions are rather speculative. Ideally, the voices of members of the First Nation community would best serve to elicit the limitations and cultural perspectives that challenge Native Americans' pursuit of such educational training. However, surveying available literature, it is evident there are several limitations to NA enrollment in STEM education.

The American Association of Medical Colleges (AAMC) recognizes that a shortage of NA physicians contributes to health disparities of this population [23]. Despite this, the number of NA students matriculating into medical school annually continues to decline. In 2014, 202 NA enrollees began studies across the United States [24]. In 2016, there were only 194 matriculants of 553 applicants [24]. It is believed that effective recruitment and retention may assist in increasing these numbers, preparing a generation of new NA physicians to care for their own communities. However, given the scarcity of NA mentors or role models in medicine, there are often few, if any examples for aspiring NA physicians to emulate [23]. Beyond this factor, there are numerous societal challenges underlying attainment of medical education for Native Americans.

The first major factor challenging the NA communities is dire poverty. 7 of the 10 poorest counties in the USA are in counties in which the primary population is NA. Additionally, $39 \%$ of NA populations living on reservations live below the federal poverty limit. Life on the reservations is reported to have high unemployment rates, with low-wages for positions offered $[25,26]$. This severely limits the access to educational resources like basic telecommunications and broadband services accessible to NA students when compared to non-NA students. Subsequently, this creates a social isolationism amongst NA students which impedes their social integration and awareness of opportunities outside of life on the reservation. This poverty further compound the technological limitation challenging NA students further because of the limitations it places on their K-12 education. Xie et al. have demonstrated from 
a survey of literature that the educational resources of a school including technology are associated with an impact on student achievement [26].

Family values also may place a role in the STEM education gap challenging NA students. There is empirical evidence that individuals from high and middle social economic social statuses generally have high education and income backgrounds, thus enabling such individuals to provide their children with the appropriate encouragement, support, educational opportunities, role-modeling, and exposure necessary for them to develop an early interest, confidence and aspiration to pursue higher education and STEM fields [27-32]. This social niche developed by parental guidance influences students to pursue certain fields because of the culture identity it creates. Children typically learn through emulation and role modeling, thus what one sees is most likely what they will want to pursue as well. The common practice embraces familiarity and association. The challenge results when one wants to step away from what is commonly practiced, as it generates a sense of isolationism. Hence, if the majority in a community does not pursue higher education for any set of circumstances, then the few individuals who decide to pursue the lesser commonly practiced may be perceived as abandoning normalcy which in itself creates social isolation. Without great strength and perseverance, such a practice can be crippling. A possible solution to this is to create a grassroots movement to encourage an interest in higher education and STEM fields which will create a new culture versus the current standard of reservation life. This will ultimately encourage younger generations of NA students to pursue training in STEM fields, who will be able to return to reservations and improve the specific challenges that they face.

\section{Discussion}

Colonization of the United States was often a violent affair. Beyond the bloodshed due to firearms, infectious diseases killed a countless number of Native Americans due to lack of immunity or medicinal treatment [33,34]. The Indian Removal Act legally permitted the forced displacement of Native Americans through the brutality of Westward expansion, relocating Western NA tribes to territory occupied by Eastern tribes. In 1830, Congress then passed an Act to legally relocate Indian tribes from the Eastern United States back to the Midwest-West of the Mississippi River [35,36]. Similarly, the United States government supported the overthrow of the nation of Hawaii 63 years later in 1893, which was originally a sovereign nation [36].

Beyond the attacks to Native American populations with violence and disease, another movement sought to eradicate NA culture-religion. In 1819, Congress began to pay missionaries to work towards conversion of tribes to Christianity [37]. This was particularly apparent in Alaska and Canada where the territory was divided into regions that were targeted by particular Christian sects to bring "civilization" while suppressing tribal life [38]. Similarly, these missionaries sought to eliminate native languages. In Hawaii, it became illegal to teach in any language besides English in 1896 [36]. These historical burdens continue to affect the NA way of life in modern society. As victims of colonization, current generations watch their predecessors bear these burdens evidenced by premature death and poverty [39]. This historical trauma created a strained relationship between the First Nations' people as a whole and the U.S. government, which resulted in their social isolation, living on dedicated 'reservations' in an attempt to protect their cultural values, people, and sacred land. Centuries of such isolationism has often created destitute living conditions and social challenges of violence, drugs, alcohol use, and poverty despite economic prosperity of certain tribes who monetarily benefit from the casino and gaming industry.

Outreach to these communities is often complicated by their very isolated, esoteric lifestyle. An example of such social barriers is characterized by a group of Miccosukee tribesmen who have dissenting opinions regarding sharing their culture with outsiders-non-Miccosukee tribe members. The Council of the Original Miccosukee Simaloee Nation of Aboriginal People have turned away from the transforming culture in favor of a way of life that more closely resembles that of their ancestors [40]. This more ancient, spiritual way of life is meant to protect future generations and life on 
the reservation from the federal government. Such conflict within the tribe leads to the maintenance of a delicate balance between maintaining traditions while prospering in the modern world [41]. These internal tribal conflicts fundamentally create an imbalanced lifestyle lacking the basic necessities of living which can be exemplified by Maslow's theory of hierarchical needs. In a paper authored by Abraham Maslow in 1943, Maslow proposes that the stages of human growth and development are pyramidal in pattern, where each subsequent higher step of development is dependent on the most fundamental physiological needs (Figure 1). It is proposed that many individuals, attaining the level of self-actualization, can successfully excel in endeavors such as higher education having met the more primal needs of survival. While many of these basic physiological needs of living are naturally provided such as air, water, and sexual instinct, many factors are not appropriately accessible such as food, shelter, sleep, and clothing; especially living on a reservation in the United States. This creates instability in the growth and development of an individual and community.

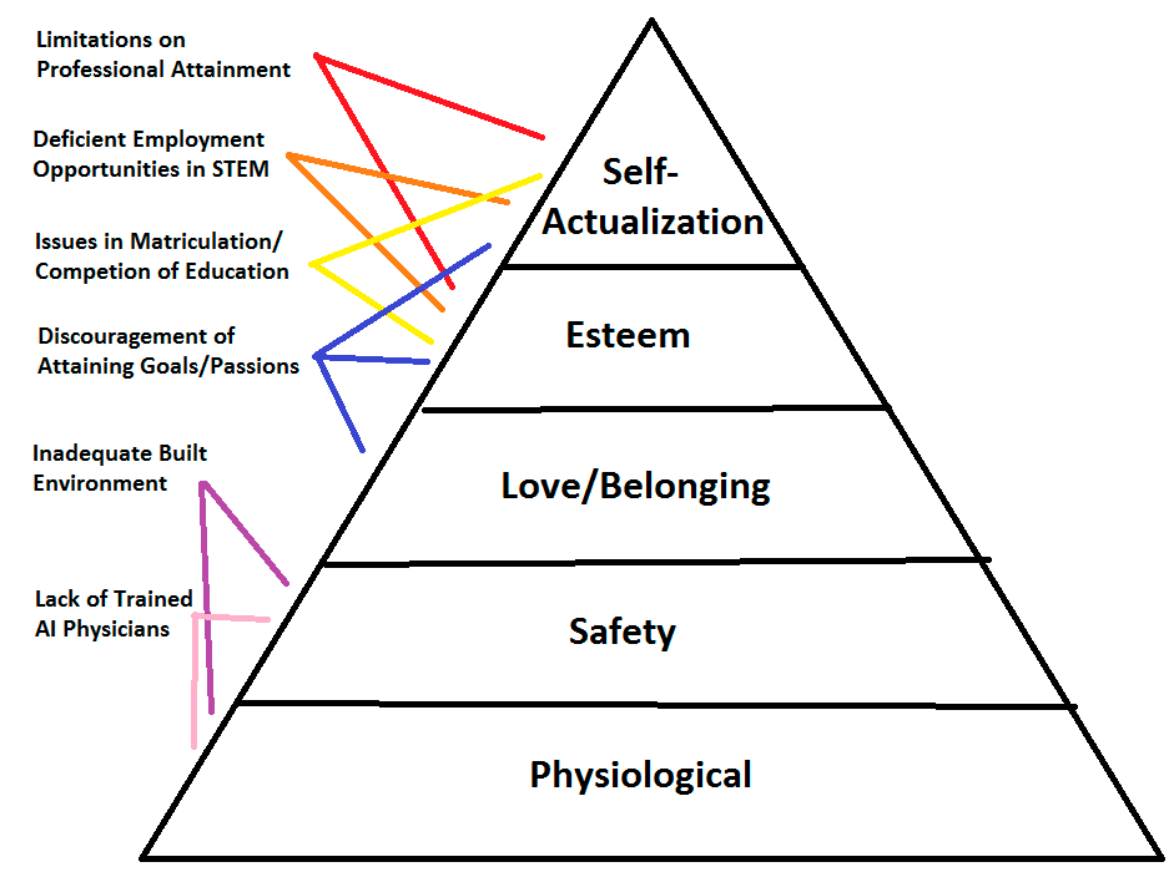

Figure 1. Visualization of the interplay between science, technology, engineering and mathematics (STEM) education and health in the context of Maslow's Hierarchy of Needs.

The impact of these instabilities in the First Nations' community centered on poor quality of living, manifests in several ways. One of the most important red-flags indicating such underlying problems is that of poor mental health, which is rampant amongst the Native American tribes. Such challenges lead to depression, substance abuse, suicide, or violence amongst tribesmen. The relationship between psychosocial and biological health is well supported.

Broadly speaking, the social determinants of health, where one lives, works and plays affect health to an equal, if not greater extent, than biological factors [42]. Meaning that health is largely determined by socioeconomic systems and cyclic disparities that continue to perpetuate poverty and inequity in NA communities [43]. Historical trends including relocation and discrimination by the federal government gives way to these circumstances. With few ties to ancestral lands and practices, the NA identity has been transformed into that dictated by the oppressors, occupying lower rungs on the Caucasian dictated social hierarchy. Physically, the built environment presents challenges for care access in NA populations. It has been established that in counties with high NA populations, the distance to screening centers for mammography and colonoscopy is much further than in other regions. This suggests that screening compliance is frequently correlated with distance to services [44]. This same observation holds true in Hawaii [45]. Additionally, the lack of facilities or perceived 
discriminatory acts by medical providers further dictate barriers to medical access and care in NA populations [46]. This is complicated by mistrust in non-Native providers, furthering the difficulties in access to care [47].

With such a cyclic pattern of self-harm as a consequence of a poor quality of living, attaining the status of self-actualization where higher education, growth and development occur is seemingly unattainable. Higher education, STEM education, medical education and health become secondary and tertiary aspirations and the Native American community erodes from within from the social instability imparted by the unfulfilled basic physiological needs.

More than $25 \%$ of the NA population lives in poverty, which is more than double that of the general population $[6,15]$. Additionally, $71 \%$ of NA individuals possess a high school diploma or GED compared to $80 \%$ of the non-NA population. This trend is observed in the early stages of education as seen in kindergarten to fourth grade, and high school dropouts $[7,20]$. Amongst the NA population, there is also a high unemployment rate ranging from $14.4 \%$ to $35 \%$ in some communities $[8,18]$. Based on a survey from New Mexico and the Mescalero Apache reservation, other risk factors include: alcohol and physical violence at home, separated or divorced parents, a close family member serving time in jail, physical abuse, neglect, suicide and sexual abuse [9].

Undoubtedly, there is a relationship between the enrollment and success in higher STEM education, medical training and disparities in NA health. By failing to train young professionals in these fields, the disparities in medicine and engineering are perpetuated. Further, the lack of NA STEM-trained engineers, contributes to the lack of a built environment and basic services conducive to healthful lifestyles.

\section{Recommendations and Conclusions}

Caring for American Indian patients is complex. Patients may not seek care, as illness is often perceived as stemming from a disharmony of spirit, body and mind, rather than being seen as a biological disease [48]. Further, individuals may be reluctant to reveal symptoms of pain for a multitude of reasons including fear of addiction to medicines, avoidance of "mind alterers", or denial of physical decline [49]. In addition to this, the historical tumultuous relationship between the non-NA "white" population and the First Nation's people imposes several barriers that prevent the NA community from receiving care. Thirdly, the social isolation of reservation life and insufficient access to care compounds the social problems plaguing the NA community.

There is a large demand across academia, industry and community for students with educational training in a discipline that is part of the STEM coalition: Science, Technology, Engineering and Mathematics. Despite STEM careers being widely recognized as an integral part of economic growth and development in the U.S. with excellent starting salaries at the bachelor's degree level and long-term job security, STEM education continues to struggle in attracting NA students to the field. Students of Native American descent are not only behind in STEM careers, but also in attaining a high school and post-secondary education. Undoubtedly, a connection between STEM training, even in primary levels with application, matriculation, and success in medical education exists. With such a glaring dearth of enrollment and completion of education, very little data and perspective from the Native American communities actually exists, leaving one to interpret the statistical data of under-enrollment/completion using the same factors as those highlighted by non-native American students which include disparities in family socioeconomic status, race, gender and cultural values. Attracting NA students to medical professional programs and STEM training programs will allow students to retain their cultural values and create a pipeline to ultimately change the culture of reservation life and community without losing historical culture. The success of these trainees hinges on effective recruitment and retention of these students by working to understand and accommodate both their educational and cultural needs. This will ultimately help to ameliorate the poor social determinants of health affecting quality of life on Indian reservations today. Such interventions may 
be applicable to other cultural communities across the globe with appropriate tailoring to the unique social conditions challenging each community.

Acknowledgments: The authors of this paper would like to dedicate this work to the First Nations' people and to the NA students across the country.

Author Contributions: Dharam Persaud-Sharma and Joseph Burns both conceived of the study, participated in its design and coordination and drafted the manuscript.

Conflicts of Interest: The authors declare no conflict of interest.

\section{References}

1. Morison, S.E. Admiral of the Ocean Sea: A Life of Christopher Columbu; Little, Brown and Company: New York, NY, USA, 1942.

2. Brown, J.W. Native American Contributions to Science, Engineering, and Medicine. Science 1975, 189, 38-40. [CrossRef] [PubMed]

3. Bennett, B.C.; Hicklin, J.R. Uses of saw palmetto (Serenoa repens, Arecaceae) in Florida. Econ. Bot. 1998, 52, 381-393. [CrossRef]

4. Mahdi, J. Medicinal potential of willow: A chemical perspective of aspirin discovery. J. Saudi Chem. Soc. 2010, 14, 317-322. [CrossRef]

5. Russell, M.L. Bayer Facts of Science Education XV: A View from the Gatekeepers-STEM Department Chairs at America's Top 200 Research Universities on Female and Underrepresented Minority Undergraduate STEM Students. J. Sci. Educ. Technol. 2012, 21, 317-324.

6. Carroll, B.; Mitchell, H.; Tambe, P.; St. John, M. Supporting Native American Students along STEM Education Pathways: Findings from an Exploratory Study of South Dakota's Educational Landscape; Inverness Research: Inverness, CA, USA, 2010.

7. U.S. Census Bureau. Profile America: American Indian and Alaska Native Heritage Month: November 2013 (CB13-FF.26); U.S. Department of Commerce: Washington, DC, USA, 2013.

8. Office of Minority Health. American Indian/Alaska Native Profile. 2014. Available online: https:// minorityhealth.hhs.gov/omh/browse.aspx?lvl=3\&lvlid=62 (accessed on 14 March 2017).

9. Indian Health Service. Trends in Indian Health, 2014 Edition; U.S. Department of Health and Human Services: Washington, DC, USA, 2014.

10. Burns, J.; Persaud-Sharma, D.; Green, D. Beyond JNC 8: Implications for Evaluation and Management of Hypertension in Underserved Populations. Acta Cardiol. 2018, in press.

11. Community Health-Indian Health Service (IHS). IHS. Gov. 2017. Available online: https:/ /www.ihs.gov / communityhealth / (accessed on 14 March 2017).

12. Behavioral Health-Community Health. IHS. Gov. 2017. Available online: https://www.ihs.gov/ communityhealth/behavioralhealth / (accessed on 14 March 2017).

13. Indian Health Service. Tracking Regional Indian Health Service Status Objectives 2011; U.S. Department of Health and Human Services: Washington, DC, USA, 2011.

14. Best Practices in Use-Domestic Violence Prevention Initiative. IHS. Gov. 2017. Available online: https: //www.ihs.gov/dvpi/bppinuse/ (accessed on 14 March 2017).

15. Environmental Health-Community Health. IHS. Gov. 2017. Available online: https://www.ihs.gov/ communityhealth/environmentalhealth/ (accessed on 14 March 2017).

16. Health Communications-Community Health. IHS. Gov. 2017. Available online: https://www.ihs.gov/ communityhealth/healthcommunications / (accessed on 14 March 2017).

17. Health Promotion-Community Health. IHS. Gov. 2017. Available online: https://www.ihs.gov/ communityhealth/hpdp/ (accessed on 14 March 2017).

18. Tobacco Prevention-Health Promotion/Disease Prevention. IHS. Gov. 2017. Available online: https: //www.ihs.gov/hpdp/tobaccoprevention/ (accessed on 14 March 2017).

19. Injury Prevention-Community Health. IHS. Gov. 2017. Available online: https://www.ihs.gov/ communityhealth/injuryprevention/ (accessed on 14 March 2017).

20. School Health-Community Health. IHS. Gov. 2017. Available online: https://www.ihs.gov/ communityhealth/schoolhealth / (accessed on 14 March 2017). 
21. Sustainability-Community Health. IHS. Gov. 2017. Available online: https://www.ihs.gov/ communityhealth/sustainability/ (accessed on 14 March 2017).

22. Sandia National Labs. Available online: http://www.ncsl.org/Portals/1/Documents/energy/Tribal_ Energy/SBegay_STEM_Background.pdf (accessed on 14 March 2017).

23. Marcinko, T. More Native American Doctors Needed to Reduce Health Disparities in Their Communities. AAMC News, 14 November 2016. Available online: https://news.aamc.org/diversity/article/nativeamerican-health-disparities / (accessed on 31 December 2017).

24. Association of American Medical Colleges. U.S Medical School Applicant and Matriculant Data Tables. AAMC. 6 October 2016. Available online: https:/ /www.aamc.org/data/facts/applicantmatriculant/86042/ factstablea2.html (accessed on 31 December 2017).

25. U.S. Census, Disparities in STEM Employment by Sex, Race, and Hispanic Origin. Available online: http:/ / www.census.gov/prod/2013pubs/acs024.pdf (accessed on 14 March 2017).

26. Economic Policy Institute. High Unemployment Means Native Americans Are Still Waiting for an Economic Recovery. Available online: http://www.epi.org/publication/high-unemployment-meansnative-americans / (accessed on 17 December 2013).

27. Xie, Y.; Fang, M.; Shauman, K. STEM Education. 1 August 2015. Available online: https://www.ncbi.nlm. nih.gov/pmc/articles/PMC4712712/ (accessed on 14 October 2017).

28. Turner, S.L.; Steward, J.C.; Lapan, R.T. Family factors associated with sixth-grade adolescents' math and science career interests. Career Dev. Q. 2004, 53, 41-52. [CrossRef]

29. Harackiewicz, J.M.; Rozek, C.S.; Hulleman, C.S.; Hyde, J.S. Helping parents to motivate adolescents in mathematics and science: An experimental test of a utility-value intervention. Psychol. Sci. 2012, 23, 899-906. [CrossRef] [PubMed]

30. Archer, L.; DeWitt, J.; Osborne, J.; Dillon, J.; Willis, B.; Wong, B. Science aspirations, capital, and family habitus: How families shape children's engagement and identification with science. Am. Educ. Res. J. 2012, 49, 881-908. [CrossRef]

31. Sjaastad, J. Sources of Inspiration: The role of significant persons in young people's choice of science in higher education. Int. J. Sci. Educ. 2012, 34, 1615-1636. [CrossRef]

32. Dabney, K.P.; Devasmita, C.; Tai, R.H. The association of family influence and initial interest in science. Sci. Educ. 2013, 97, 395-409. [CrossRef]

33. Osorio, J.K.K. Dismembering Lahui: A History of the Hawaiian Nation to 1887; University of Hawaii Press: Honolulu, HI, USA, 2002.

34. Young, T.K. The Health of Native Americans; Oxford University Press: New York, NY, USA, 1994.

35. Hendrix, L.R. Health and Health Care of American Indians and Alaska Native Elders; Stanford Geriatric Education Center: Stanford, CA, USA, 2001. Available online: https:/ / web.stanford.edu/group/ethnoger/ americanindian.html (accessed on 14 March 2017).

36. Apology Bill. Pub. L. No. 103-150. 1993. Available online: www.capitol.hawaii.gov/session1999/bills/ HR201_htm (accessed on 1 July 2014).

37. Easley, C.; Charles, G.; La Bell, J.; Smith, S.L. Boarding School: Historical Trauma among Alaska's Native People; National Resource Center for American Indian, Alaska Native, and Native Hawaiian Elders: Anchorage, AK, USA, 2005.

38. Lucas, P.F.N. E Ola Mau Kākou I Ka 'Ōlelo Makuahine: Hawaiian Language Policy and the Courts. Hawaii. J. Hist. 2000, 24, 1-28.

39. Sotero, M.M. A Conceptual Model of Historical Trauma: Implications for Public Health Practice and Research. J. Health Disparities Res. Pract. 2006, 1, 93-108.

40. Gillis, C. Voices of the Everglades. News Press, 2014. Available online: https://www.news-press.com/story/ life/outdoors / 2014/04/28/voices-of-the-everglades-florida-indians-pay-price-for-prosperity /8403947/ (accessed on 14 March 2017).

41. Jarrell, A. View of Organ Donation Shifting in Native Culture. Capital Journal. 27 January 2013. Available online: https:/ / www.nativetimes.com/48-life/health/8351-view-of-organ-donation-shifting-in-nativeculture (accessed on 14 March 2017).

42. World Health Organization (WHO). The Rio Political Declaration of the World Conference on Social Determinants of Health; WHO: Geneva, Switzerland, 2012. 
43. Marmot, M. Achieving Health Equity: From Root Causes to Fair Outcomes. Lancet 2007, 370, 1153-1163. [CrossRef]

44. Towne, S.D., Jr.; Smith, M.L.; Ory, M.G. Geographic Variations in Access and Utilization of Cancer Screening Services: Examining Disparities among American Indian and Alaska Native Elders. Int. J. Health Geogr. 2014, 13, 18. [CrossRef] [PubMed]

45. Braun, K.L.; Mokuau, N.; Hunt, G.H.; Kaanoi, M.; Gotay, C.C. Supports and Barriers to Cancer Survival for Hawaii's Native People. Cancer Pract. 2002, 10, 192-200. [CrossRef] [PubMed]

46. Shavers, V.L.; Fagan, P.; Jones, D.; Klein, W.M.; Boyington, J.; Moten, C.; Rorie, E. The State of Research on Racial/Ethnic Discrimination in the Receipt of Health Care. Am. J. Public Health 2012, 102, 953-966. [CrossRef] [PubMed]

47. James, A.S.; Filippi, M.K.; Pacheco, C.M.; Cully, L.; Perdue, D.; Choi, W.S.; Greiner, K.A.; Daley, C.M. Barriers to Colorectal Cancer Screening among American Indian Men Aged 50 or Older, Kansas and Missouri, 2006-2008. Prev. Chronic Dis. 2013, 10, E170. [CrossRef] [PubMed]

48. Mulkey, P.; Lacock, M.; Scott, K. Guidelines for Health Care Providers Interacting with American Indian Patients and Their Families; Metropolitan Chicago Healthcare Council: Chicago, IL, USA, 2004.

49. Handzo, G. A Dictionary of Patients' Spiritual \& Cultural Values for Health Care Professionals; Healthcare Chaplaincy Network: New York, NY, USA, 2009.

(C) 2018 by the authors. Licensee MDPI, Basel, Switzerland. This article is an open access article distributed under the terms and conditions of the Creative Commons Attribution (CC BY) license (http:/ / creativecommons.org/licenses/by/4.0/). 